\title{
Recurrent severe hypernatremia in a young RCSI man with hydrocephalus and normal osmoregulatory function
}

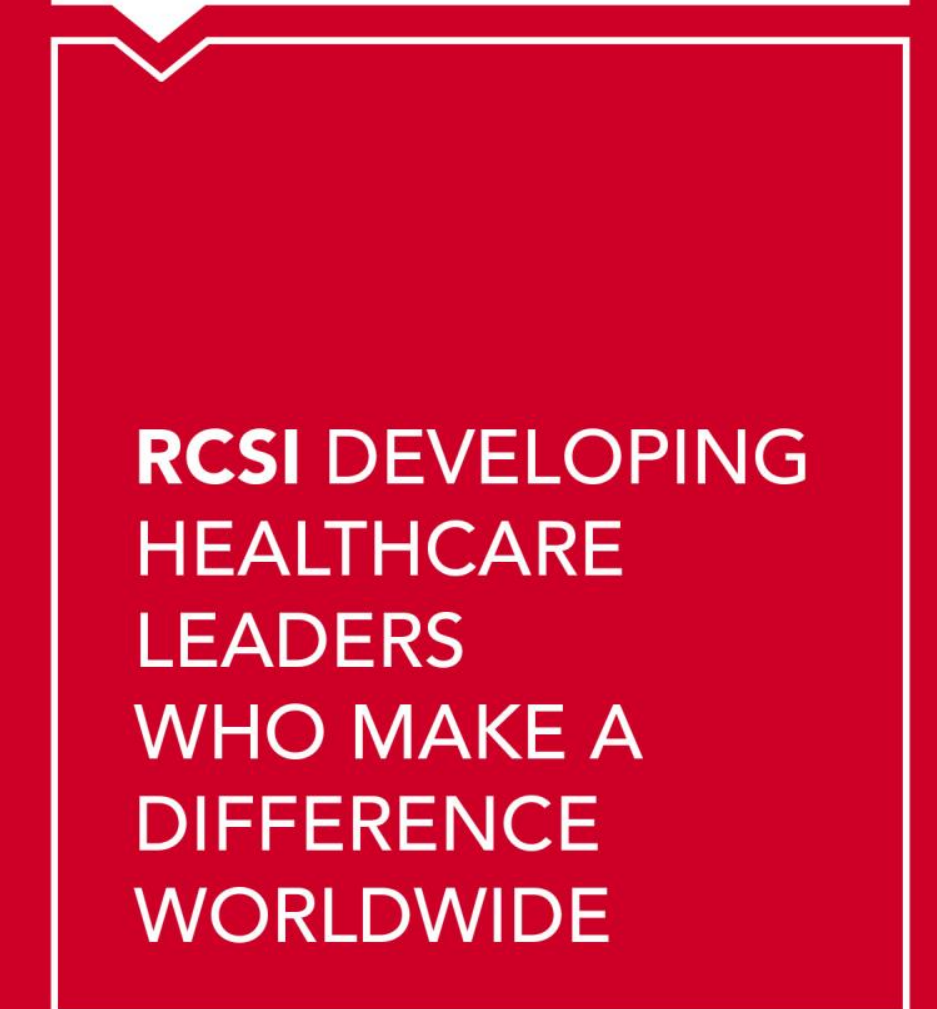

\author{
Tudor $\mathrm{RM}^{1}$, Hannon $\mathrm{AM}^{1}$, Tormey $\mathrm{WT}^{2}$, Sherlock $\mathrm{M}^{1}$, Thompson $\mathrm{CJ}^{1}$ \\ ${ }^{1}$ Academic Department of Endocrinology and Diabetes Beaumont Hospital/RCSI Medical School Dublin \\ ${ }^{2}$ Departement of Chemical Pathology Beaumont Hospital/RCSI Medical School Dublin
}

\section{Context}

Chronic hypernatremia is a rare clinical entity, encountered predominantly in the elderly population.

In the younger population, chronic hypernatremia is often a consequence of failure to generate thirst in response to osmotic stimuli.

We report the first case of a patient with a disconnect between normal osmoregulated thirst and abnormal drinking behaviour.

\section{Case report}

A 24 year old man presented with gait instability, myalgia, and cognitive decline. He was dehydrated and had marked facial dysmorphism. No focal neurological signs were noted on examination. The patient's biochemical picture was consistent with hypernatremic dehydration (Table 1 ).

Table 1. Results of laboratory investigations during admission

\begin{tabular}{|l|l|l|l|l|l|}
\hline Parameter & Day 1 & Day 2 & Day 3 & Day 4 & Day 5 \\
\hline $\begin{array}{l}\mathrm{Na} \\
\text { (ref 133-146 mmol/L) }\end{array}$ & 175 & 170 & 161 & 150 & 140 \\
\hline $\begin{array}{l}\mathrm{K} \\
\text { (ref 3.5-5.3 mmol/L) }\end{array}$ & 2.2 & 2.3 & 4.1 & 4.2 & 3.9 \\
$\begin{array}{l}\text { Urea } \\
\text { (ref 2.7-7.8 mmol/L) }\end{array}$ & 16.9 & 15.6 & 12.7 & 11.3 & 8 \\
\hline $\begin{array}{l}\text { Creatinine } \\
\text { (ref 64-104 mmol/L) }\end{array}$ & 135 & 128 & 108 & 90 & 76 \\
\hline $\begin{array}{l}\text { Posm } \\
\text { (ref 275-295 mosm/kg) }\end{array}$ & 374 & - & 344 & - & 296 \\
\hline $\begin{array}{l}\text { Uosm } \\
\text { CK } \\
\text { (ref 0-170 U/L) }\end{array}$ & 894 & 963 & - & - & 496 \\
\hline
\end{tabular}

MRI brain showed marked hydrocephalus (Image 1).

The patient was treated with IV dextrose and recovered without neurologic sequelae.

A reset osmostat for thirst and AVP release was suspected and following discharge, the patient underwent $5 \%$ saline infusion. ${ }^{1}$ Plasma AVP rose from 1.4 to $7.3 \mathrm{pmol} / \mathrm{I}$ and linear regression analysis defined a normal osmotic threshold for AVP release of 283 $\mathrm{mOsm} / \mathrm{kg} ; \mathrm{pAVP}=0.27$ (pOsm-283), $\mathrm{r}=0.88, \mathrm{p}=0.002$. Thirst (visual analogue scale) rose appropriately, with a normal osmotic threshold: thirst $=0.31$ (pOsm -283$), r=0.98, p<0.0001$. The patient therefore had normal osmoregulatory function (Fig 1).

However, in the 30 mins following infusion, the patient only drank $400 \mathrm{mls}$ water, despite normal thirst dynamics (normal water intake $700-1200 \mathrm{mls}$ ).

Therefore, there was a disconnect between normal osmoregulated thirst and his abnormal drinking behaviour.

The patient was recommended to have a fixed fluid intake of 2-3 litres daily. He remained eunatremic until ten years later, when during febrile illness, his fluid intake fell and he again presented with hypernatremic dehydration.

The patient has had no progression in his neuroimaging and no development of neurological features after 10 years of follow-up.

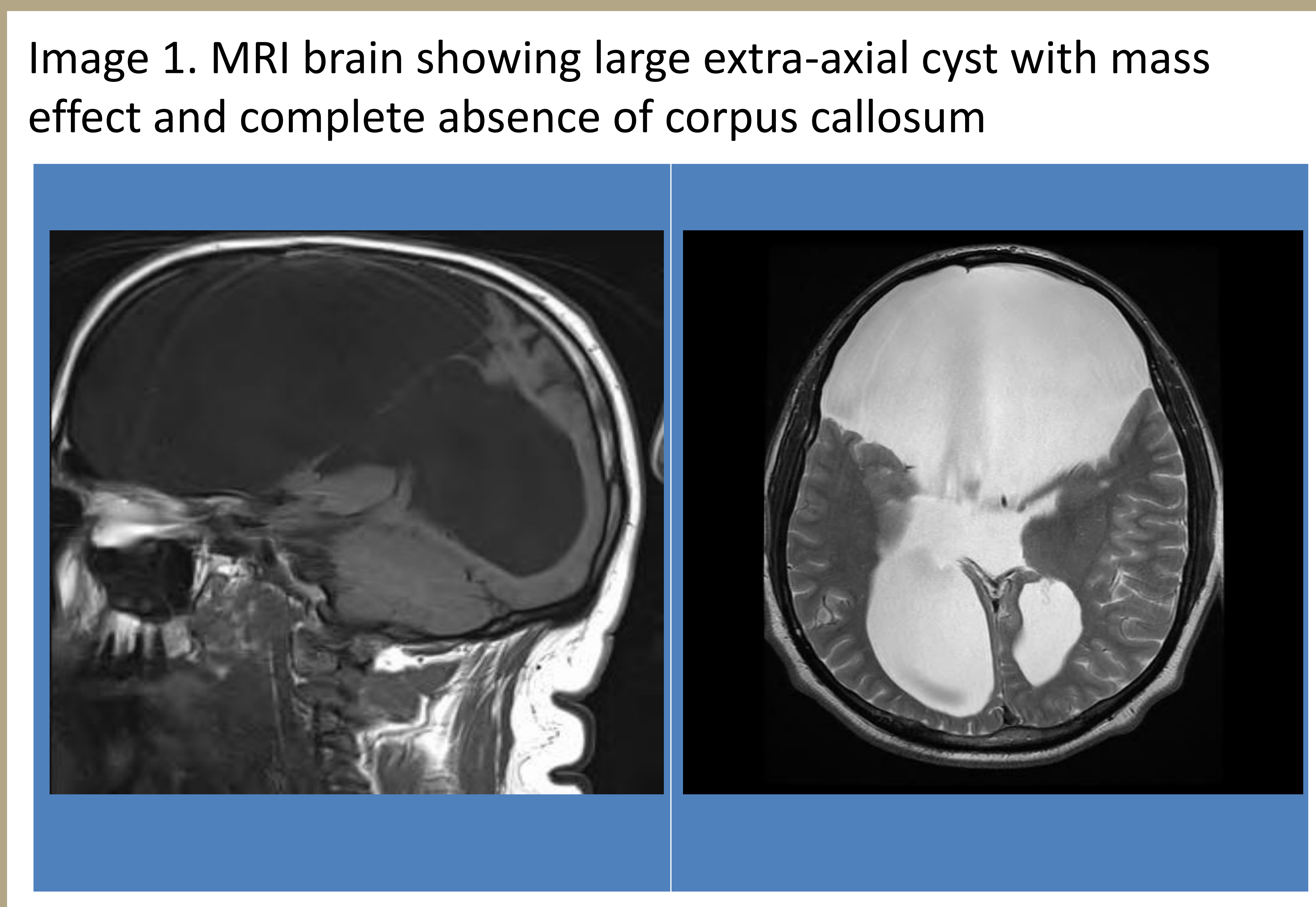

Fig 1. Schematic representation of plasma vasopressin release and thirst after infusion of hypertonic saline in our patient. The response is within normal range. ${ }^{1}$
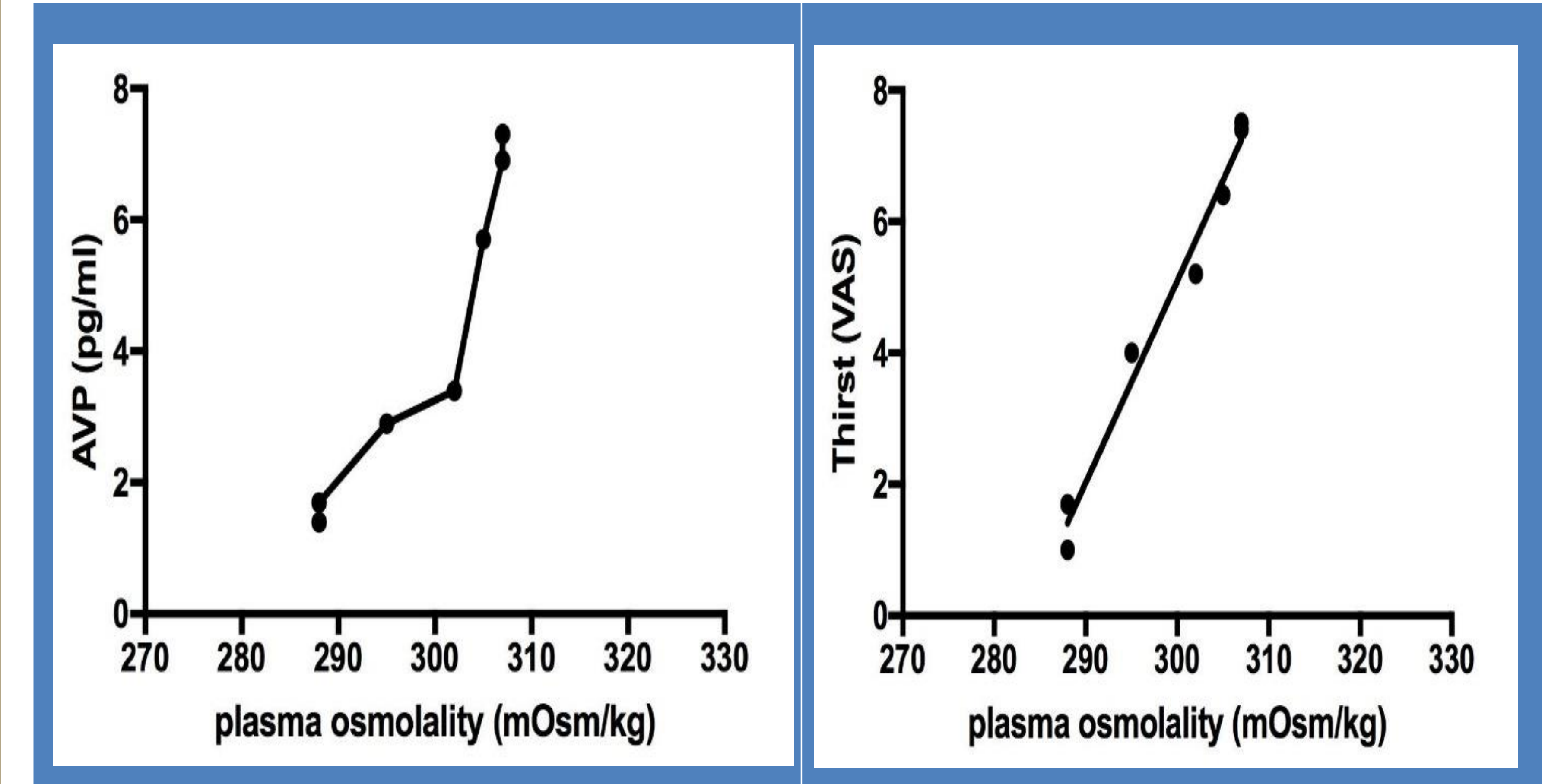

Key points

- Our patient has an unique disconnect between the osmoregulatory function and fluid intake.

- The mechanism of this abnormality is unknown.

- It is difficult to dissociate this patient's abnormal drinking behaviour from his marked hydrocephalus, as distortion of the complex anatomic structures that translate thirst appreciation into the central drive to drink seems inevitable. ${ }^{3}$

- Learned behaviour with fixed fluid intake has prevented day today hypernatremia, but the patient remains vulnerable to severe life threatening hypernatremia during intercurrent febrile illnesses.

\section{References}

1. Thompson CJ, Bland J, Burd J et al.: The osmotic thresholds for thirst and vasopressin release are similar in healthy man. Clin Sci (Lond) 1986: 71(6):651-6.

2. Baylis $\mathrm{PH}$, Thompson $\mathrm{CJ}$ : Osmoregulation of vasopressin secretion and thirst in health and disease. Clin Endocrinol. 1988; 29:549-576.

3. Egan G, Silk T, Zamarippa F, et al: Neural correlates of the emergence of consciousness of thirst. Proc Natl Acad Sci U S A. 2003; 100(25):15241-6. 